\title{
An Assessment of Intra-household Allocation of Food: A Case Study of the Urban Poor in Kandy
}

\author{
Ishara Rathnayake and Jeevika Weerahewa*
}

\begin{abstract}
Malnutrition among children and women continues to be one of the major problems in Sri Lanka despite the food and nutritional intervention programs implemented since independence. The objectives of this study were to find out whether there is calorie malnutrition among the urban poor in Kandy and to find out the determinants of the intra-household allocation of calories. Calorie adequacy ratios of fathers, mothers and children were compared to find out whether there is calorie malnutrition among family members. Relative calorie allocation of individuals was regressed with socioeconomic variables to find the determinants of the intra-household calorie allocation. Primary data collected using a structured questionnaire from sixty households in the lower income group in urban Kandy was used for the analysis. Results show that there was a significant difference among calorie adequacy ratios of fathers, mothers and children. Fathers have the highest and children have the lowest mean calorie adequacy ratios. Regression results indicate that income of mother and family size have significant positive and negative impacts respectively on mother's relative calorie allocation. Results also show that there was an age and gender biased calorie allocation within the family. Income of mother had a negative effect on children's calorie allocation. Though expansion in employment opportunities could alleviate malnutrition among women, it may aggravate malnutrition among children.
\end{abstract}

\section{Introduction}

Successive governments of Sri Lanka have paid attention to improving the nutritional status of the nation. However, malnutrition continues to be one of the major problems in Sri Lanka. The types of malnutrition in Sri Lanka include protein energy malnutrition and micro nutrient deficiencies such as iron, iodine and vitamin A. Furthermore, malnutrition is prominent among women and

The authors are, respectively, Final Year Undergraduate Student at the time the study was conducted, and Senior Lecturer in Agricultural Economics, University of Peradeniya. 
children (Central Bank, 1998). According to the Department of Census and Statistics (1999), a large number of the women do not get their daily calorie requirement and their daily recommended levels of vitamins, iron and iodine. As a result, protein energy malnutrition, anemia and goiter are common among them. Nearly $14 \%$ of children in the age group of 3-59 months are stunted. Furthermore, there is a significant gender differential in stunting of children. More females are stunted than males (Wijesinghe and Wilfred, 2001). Furthermore, nutritional statistics show disparities among different sectors in the economy. Nearly $34 \%$ of children in the estate sector show chronic under nutrition. Mothers in the urban, rural and estate sectors $(21 \%, 43 \%$ and $58 \%$ respectively) are undernourished. Children in the metro Colombo show the lowest proportion of stunting (7\%) followed by children in the other urban and rural areas (Wijesinghe and Wilfred, 2001).

According to the Central Bank (1998), malnutrition in Sri Lanka is due to low income and inappropriate dietary habits. Malnutrition could also be due to inequitable allocation of food among family members (Senauer, et al., 1988). Most of the developing countries have a pattern of intra-household allocation of food, which favor males over females and household elders (Senauer, et al., 1988). For example, Gross and Underwood (1971), in their classic study of energy flow among workers in Brazil, showed that male wage earners received preference in the allocation of calories within the household. They were fed first, with a sufficient quantity to sustain their work, often at the expense of children and women, who received what was left after the male's energy needs. It was found that women's work and income have positive impacts on the nutrient intake of household members, either because women allocate more of their income directly to the food budget or because they make the intrahousehold distribution of food more equitable when they contribute to the food budget.

Senauer et al., (1988), conducted a survey to find out the determinants of the intra-household allocation of food in the rural Philippines. The data utilized in this analysis were from a household survey conducted in 1983-84 in three rural provinces of the Philippines. They have gathered information regarding household food expenditure, consumption, household size and composition, earnings by source and individual, and time allocation of the husband and wife. For a sub sample of 140 households, individual food consumption data for a 24-hour 
period were collected using the foodweighing method.

In Sri Lanka, though there are many socio-economic studies conducted to examine nutritional status of individual families, intrahousehold food allocation was not considered as one of the causes of malnutrition (Gunasekara, 1999 and Thudawe, 1986, 2002). The objectives of this study are (i) to examine whether there is calorie malnutrition within the household members, and (ii) to find out the socio-economic factors affecting inequitable allocation of calories.

This paper is organized as follows. The next section provides the methodology showing measures of inequitable allocation and factors affecting inequitable allocation. Section three presents the method of data collection. Section four presents the results and the final section presents conclusions and policy implications.

\section{Methodology}

There are different indicators, which can be used to measure nutritional status of an individual. The commonly used measures are nutrient intake, calorie adequacy ratio and relative calorie allocation (Senauer, et al., 1988). Each indicator has its own advantages and disadvantages. Nutrient intake is the amount of nutrients taken by a person. Food conversion tables are used to convert the amount of food into the amount of nutrients. Usually calorie intake is expressed as the amount of kilocalories per person per day. Though this measure is easy to calculate, it neither shows the adequacy of nutrients as it does not compare intake and recommended levels of nutrients nor does it show inequality of intra-household food allocation.

The ratio between calorie intake and the recommended level is known as calorie adequacy ratio (CAR). The advantage of this indicator is that it can be used to measure calorie malnutrition though it does not give any idea about inequality of intrahousehold food allocation. CAR can be calculated for individuals and for households. The individual CAR (ICAR) is derived by dividing an individual's calorie intake (ICI) by his or her recommended daily allowance (IRDA) for that nutrient and multiplying by 100 .

$$
I C A R=\frac{I C I}{I R D A} \cdot 100
$$

If ICAR is equal to one then the individual is taking the recommended calorie level. If ICAR is greater than or less than one then the individual is taking higher than or 
less than their recommended levels respectively.

Household is defined as a group of individuals who reside together, pool all or most of their income, and basically share the same food supply. Household CAR (HCAR) gives an idea about the average calorie intake when compared to the recommended levels for the entire household. The HCAR is derived by dividing the household total calorie intake (HCI) (sum of the individual calorie intake of all the family members), by total recommended daily allowance for the entire household (HRDA) (sum of the RDA of all the family members), and multiplying by 100 .

$$
H C A R=\frac{H C I}{H R D A} \cdot 100
$$

Relative calorie allocation (RCA) is used in order to get the ICAR in relation to that of the average of the entire household. The RCA is derived by dividing the ICAR by the HCAR.

$$
R C A=\frac{I C A R}{H C A R}
$$

If this ratio is greater than or less than one it implies that there is an inequitable allocation of calories among family members. If it is equal to one it indicates that there is an equitable allocation of calories among family members. This indicator can be used to assess the inequality if any in intra-household food allocation.

In this study, to find out whether there are any differences in allocation of calories among fathers, mothers and children of the sample, the ICAR values of different individuals were compared using analysis of variance (ANOVA) and mean separation. Mean values of ICARs of fathers, mothers and children of the sample were used to test the null hypothesis that "there is no difference among the mean values of ICARs of fathers, mothers and children in the sample".

As used by Senauer et al., (1988), a regression analysis was used to find out the factors affecting inequitable allocation of calories. RCA was used as the dependent variable to represent the intra-household calorie allocation. Selected socio-economic factors were used as independent variables.

Socio economic factors used in the analysis were income of father, income of mother, age of father, age of mother, education of father, education of mother, number of adults in the household, number of 
children in the household, age of child, gender of child, birth order of child and ethnicity. Education levels of fathers and mothers were treated as continuous variables. It was measured as the number of years of schooling. The variable gender was considered as a dummy variable and males were given one and females were given zero. Birth order of child shows his/her rank in the family. For example, for a family with three children, the birth order of the eldest child is one, the second child's birth order is two and the birth order of the youngest child is three. Three types of ethnic groups are considered; Sinhalese, Tamil and Muslim, and ethnicity also was treated as a dummy variable.

The impacts of the above mentioned socio-economic variables on RCA are mostly uncertain and depends on the society under consideration. Income of mother may have a positive effect on children's RCA because mothers are more likely to allocate extra resources under their control to children than the fathers. Income of father may have a positive effect on his RCA but a negative effect on child's RCA because in lower income groups, most of the males spend money on alcohol and cigarettes. Education levels of the parents may have a positive effect on the RCA of themselves and on children. In Sri
Lanka, lack of knowledge is considered as one of the major reasons for malnutrition. Family size has an uncertain impact on RCA of different individuals. When number of children in the household increases, RCA of all family members in the household would decrease, if all these children are dependents. When number of adults, who earns an income, increases, RCA of at least some of the family members might increase. Age of child, gender and birth order can influence child's RCA. Boys and lower birth order children are found to be favored especially in Asian Countries.

\section{Method of Data Collection}

A field survey was conducted in order to gather necessary information on individual food consumption and household characteristics using a structured questionnaire. The study was conducted within the Kandy Municipal Area. Sixty households were selected representing the lower income group within the Kandy Municipal Limits. The average monthly income of the sample was below Rs. 6,000/=. Random samples were drown from each Grama Sevaka division and Suduhumpola, Deiyannewela, Mahaiyawa and Bahirawakanda Grama Sevaka divisions were selected. 
General household information such as income of parents, ages of the family members, education levels of the parents, birth order and gender of the children and ethnicity were obtained. Individual food consumption data for a 24-hour period were collected by recall. Ideally, data should have been collected using an anthropological approach. Enumerators should have lived with the respondent family for about a week and food consumption of different individuals should have been recorded by the enumerators. Given the scope of this study and resources available, the recall method was used.

Data on intake of different types of food such as rice, wheat flour and bread, was converted in to calorie intake using food conversion factors. RDA obtained from secondary sources was used to calculate ICAR and RCA.

\section{Results and Discussion}

Results showing ICAR of different family members to confirm the status of malnutrition are presented in the following section. Next section shows the determinants of RCA.

\section{State of malnutrition}

Table 1 shows the mean values of calorie intake, RDA and ICAR of fathers, mothers and children. The overall average ICAR of the sample is 0.85 . It indicates on average individuals in the sample are getting only $85 \%$ of their recommended levels. The difference indicates that the ICAR of the people in the survey areas is less when compared to total urban sector in Sri Lanka because malnutrition is not prominent in the total urban sector in Sri Lanka. (Department of Census and Statistics, 1999). In this sample, mean ICAR of fathers is 0.98 . The mean ICAR of mothers and children are 0.90 and 0.74 respectively. Among children, boy's ICAR (0.78) is greater than that of girls (0.72). Among boys and girls, children below five years of age have relatively higher ICAR than that of above five years.

ICARs of fathers, mothers and children were compared using ANOVA to test whether there is no difference among mean values of ICARs of fathers, mothers and children. According to the Table 2, probability value of the ANOVA is 0.0001 and null hypothesis was rejected. This result indicates that there is a significant difference among mean values of ICAR of fathers, mothers and children. According to the results of mean separation, the three ICARs are significantly different from each other. Samarasinghe et al. (1990) 
also indicated that males consume more calories and proteins than females among Indian Tamil workers in tea plantations in Sri Lanka.

According to the results presented in the previous section, the mean ICARs are low for mothers and children in the sample. Therefore determinants of RCA were analyzed using multiple regression analysis only for mothers and children.

\section{Determinants of RCA}

Regression equations which were used to find out the determinants of RCA of mothers were estimated using four models i.e. $\log$-linear, $\log$ $\log$, linear-log and linear. According to the goodness of fit criteria the best-fit model is the linear model and hence the following section presents only the results of the linear model.

Table 1: $\quad$ Mean values of calorie intake, RDAs and CARs of different members

\begin{tabular}{llll}
\hline Group & $\begin{array}{l}\text { Mean of } \\
\text { the calorie } \\
\text { intake } \\
\text { (k cals) }\end{array}$ & $\begin{array}{l}\text { Mean RDA } \\
\text { (k cals) }\end{array}$ & Mean ICAR \\
\hline Average & 1803.04 & 2051.81 & 0.85 \\
Fathers & 2329.47 & 2381.12 & 0.98 \\
Mothers & 1644.66 & 1820.33 & 0.90 \\
Children & 1435.00 & 1954.00 & 0.74 \\
Girls (mean) & 1392.10 & 1963.90 & 0.72 \\
Girls (1-5 yrs.) & 1074.60 & 1406.00 & 0.76 \\
Girls (Above 5) & 1516.00 & 2181.50 & 0.69 \\
Boys (mean) & 1938.00 & 1503.95 & 0.78 \\
Boys (1-5 yrs.) & 1397.00 & 1112.80 & 0.79 \\
Boys (Above 5) & 2209.20 & 1699.50 & 0.77 \\
\hline
\end{tabular}


Table 2: $\quad$ ANOVA results

\begin{tabular}{lcc}
\hline & Mean of ICAR & P value \\
\hline Fathers & 0.98 & 0.0001 \\
Mothers & 0.90 & \\
Children & 0.74 & \\
\hline
\end{tabular}

The adjusted $R^{2}$ value and $R^{2}$ value in this model are 0.258 and 0.206. According to Table 3, the coefficients of the income of mother, education of mother and family size are $0.332, \quad 0.876$ and -0.033 respectively. Income of mother and family size variables are statistically significant at $10 \%$ and $5 \%$ significant levels respectively. These results indicate that when income of mother is increased by one unit the RCA will be increased by 0.332 and when family size increases by one more member, RCA will be decreased by 0.033 . The later is due to the fact that additional members are dependents, which lead to a reduction in per individual calorie intake. Though it was expected that education has a positive impact on RCA, education of mother does not have a significant impact on mother's RCA.

A separate regression was estimated to find out the determinants of RCA of children using four models i.e. $\log$-linear, $\log$ $\log$, linear-log and linear. According to the goodness of fit criteria the best-fit model is the linear model and hence the following section presents only the results of the linear model.

In this model the $\mathrm{R}^{2}$ value and the adjusted $R^{2}$ values are 0.182 and 0.113. According to Table 4, the coefficients of the income of mother, gender of child and birth order of child variables are $-0.410,0.078$ and -0.020 respectively and are statistically significant. Income of father, education of father, number of children and age of child do not have any significant impact on child's RCA. According to these results when income of mother increases by one unit the child's RCA decreases by 0.41 . This may be due to less time available for childcare, when mothers are involved in working. As expected, gender of child significantly affects the RCA at 5\% significant level. The coefficient is 0.078 , which means that boy's RCA is 0.078 units higher than girls. Birth order of child has a significant negative effect on RCA. The coefficient for birth order of child variable is -0.02 , which means that the higher the rank in the family, the lower the RCA. However, this 
negative coefficient does not imply malnutrition as reflected by CAR.

Ethnicity did not seem to have significant impacts on RCA of mothers and children and hence was excluded from the analysis.
The results of this study are consistent with past findings (Senauer, et al., 1988) except for the variables income of mother and number of children on RCA of children.

Table 3:

Regression results of mother's RCA

\begin{tabular}{lcrl}
\hline $\begin{array}{l}\text { Independent } \\
\text { Variable }\end{array}$ & Coefficient & t-statistic & P value \\
\hline Intercept & 1.120 & 11.92 & 0.000 \\
Income of mother & 0.332 & 1.76 & $0.084 * *$ \\
Education of mother & 0.876 & 1.53 & 0.132 \\
Family size & -0.033 & -2.51 & $0.016 *$ \\
$* \quad=$ Significant at 5\% significant level & & \\
$* *=$ Significant at 10\% significant level & & \\
\end{tabular}

Table 4: $\quad$ Regression results of child's RCA

\begin{tabular}{lccl}
\hline $\begin{array}{l}\text { Independent } \\
\text { Variable }\end{array}$ & Coefficient & t-statistic & P value \\
\hline & 0.955 & 9.66 & 0.000 \\
Income of father & 0.126 & 1.06 & 0.290 \\
Income of mother & -0.410 & -2.30 & $0.021^{*}$ \\
Education of father & -0.622 & -0.904 & 0.369 \\
No. of children & 0.002 & 0.827 & 0.410 \\
Age of child & -0.477 & -1.33 & 0.186 \\
Gender of child & 0.078 & 2.33 & $0.028 *$ \\
Birth order of child & -0.020 & -1.80 & $0.069 * *$ \\
$*$ = Significant at 5\% significant level & & \\
$* *$ = Significant at 10\% significant level & &
\end{tabular}




\section{Conclusions and Policy Implications}

Results show that there is a significant difference among mean values of the ICAR of fathers, mothers and children. The mean ICAR of fathers is close to one showing that malnutrition is not common among the fathers.

According to the results of the regression analysis, income of mother has a positive effect on mother's RCA; however it has a negative effect on child's RCA. These results imply that though by increasing income of mother it is possible to increase mother's RCA, it will reduce child's RCA. Hence, provision of employment opportunities for mothers may lead to undesirable impacts on nutritional status of children, though it improves the nutrition of mothers. This points to the need for public and private sector institutions to provide day care facilities.

Birth order of child and gender do have effects on child's RCA. According to the findings of this study, RCA of boys is higher than that of girls. Birth order of child has a negative effect on his or her RCA. Hence it can be recommended to target female children of a higher birth order, in planning nutritional intervention programs.
These results however should be considered as suggestive than conclusive. Further studies on this line using larger samples to cover a number of geographical areas will be required to confirm these findings. For such studies, it is recommended to use the weighing method to accurately calculate the food intake of the household and to have close interactions between the respondent household and the enumerators over a sufficient period of time.

\section{References}

Central Bank of Sri Lanka (1998). Economic Progress of Independent Sri Lanka. Central Bank of Sri Lanka, Colombo.

Gross, D. and B. Underwood (1971). Technological Change and Caloric Cost; Sisal Agriculture in Northeastern Brazil, M. Antro. 7:724-740.

Gunasekara, H.R. (1999). Nutrition Status of Children in Sri Lanka, Sri Lankan Journal of Population Studies, 12:5773.

Samarasinghe, V., S. Kiribamune and W. Jayatilake (1990). Maternal Nutrition and Health Status of Indian Tamil Female Tea Plantation 
Workers in Sri Lanka, International Center for Ethnic Studies, Kandy, Sri Lanka.

Senauer, B., M. Garcia and E. Jacinto (1988). Determinants of the Intra-household Allocation of Food in the Rural Philippines. American Journal of Agricultural Economics, 70(1):170-179.

Department of Census and Statistics (1999). Statistical Abstract of the Democratic Socialist Republic of Sri Lanka, Colombo, Sri Lanka.

Tudawe, I. (1986). Kirindi Oya Irrigation and Settlement Project. Dietary Intake and
Nutrition Status Survey, Colombo.

Tudawe, I. (2002). Food Demand and Energy Adequacy: Implications for the Poor, Sri Lanka Economic Journal, 73108.

Wijesinghe, N.G. and N.D. Wilfred (2001). State of Urban Nutrition in Sri Lanka Seminar on the Development of Training Curriculum on Nutrition Promotion for Addressing Challenges of Urban Nutrition, Shandong, China. 